\title{
Evaluation of wastewater reclamation technologies based on in vitro and in vivo bioassays
}

\author{
Nan $\mathrm{Cao}^{a}$, Min Yang ${ }^{a, *}$, Yu Zhang ${ }^{a}$, Jianying $\mathrm{Hu}^{b}$, Michihiko Ike ${ }^{c}$, Junji Hirotsuji ${ }^{d}$, \\ Hisae Matsui ${ }^{\mathrm{c}, d}$, Daisuke Inoue ${ }^{\mathrm{c}}$, Kazunari Sei ${ }^{\mathrm{c}}$ \\ ${ }^{a}$ SKLEAC, Research Center for Eco-Environmental Sciences, Chinese Academy of Sciences, Beijing 100085, China \\ ${ }^{\mathrm{b} C o l l e g e ~ o f ~ U r b a n ~ a n d ~ E n v i r o n m e n t a l ~ S c i e n c e, ~ P e k i n g ~ U n i v e r s i t y, ~ B e i j i n g ~ 100871, ~ C h i n a ~}$ \\ ${ }^{\mathrm{c}}$ Division of Sustainable Energy and Environmental Engineering, Graduate School of Engineering, Osaka University, 2-1 Yamadaoka, Suita, \\ Osaka 565-0871, Japan \\ dMitsubishi Electric Corporation Advanced Technology R\&D Center, Amagasaki-Hyogo 661-8661, Japan
}

\section{A R T I C L E D A T A}

Article history:

Received 21 February 2008

Received in revised form

30 September 2008

Accepted 13 October 2008

Available online 2 December 2008

Keywords:

Ecotoxicity

Genotoxicity

Hatching success

RAR activity

Secondary effluent

Reclamation technologies

\begin{abstract}
A B S T R A C T
When municipal secondary effluent is used as the main supplementation water source for surface water bodies, its potential adverse ecological effects should not be neglected. The objective of this work was to investigate the effectiveness of several technologies, i.e. combination of coagulation and sand filtration (CSF), ultraviolet (UV) irradiation, chlorination, ozonation, ultrafiltration (UF) and reverse osmosis filtration (RO), on the removal of acute ecotoxicity, genotoxicity and retinoic acid receptor (RAR) agonist activity from the municipal secondary effluent. The effects of treated effluents on the development of Japanese medaka (Oryzias latipes) embryos were also evaluated. The secondary effluent exhibited a mutagenic effect on Salmonella typhimurium strain TA 1535/pSK1002, acute invertebrate toxicity to Daphnia magna, and weak RAR $\alpha$ activity. RO and ozonation demonstrated remarkable removals of the genotoxic effect, acute toxicity and RAR activity from secondary effluent, while chlorination could elevate both genotoxicity and acute toxicity. CSF, UV, UF, chlorination as well as RO could decrease the 4-day mortality of medaka embryos and accordingly increase the hatching success rate, comparing with the secondary effluent. Ozonation at $4 \mathrm{mg} / \mathrm{l}$ and higher doses, however, elicited significantly higher 4-day mortality, leading to the reduction of the hatching success rate.
\end{abstract}

(c) 2008 Elsevier B.V. All rights reserved.

\section{Introduction}

With its rapid economical development, China has experienced growing water crisis during the last two decades, both in terms of water scarcity and quality deterioration. Effluent from municipal sewage treatment plants (STPs) has recently been focused as a novel water resource because of its relatively stable quality and quantity properties. In some northern cities in China, which are in serious shortage of surface water, the use of reclaimed municipal wastewater as a major supplementation water source for rivers and lakes is considered to be an important countermeasure to the increasing water crisis. However, the secondary effluent has been found to cause some adverse aqua-ecological effects. Aguayo et al. (2004) found that the effluent from 7 investigated STPs all showed toxic effects to Daphnia magna, while some samples showed estrogenicity and teratogenicity. Dizer et al. (2002) reported that samples taken from a river accepting the secondary effluent caused genotoxic

\footnotetext{
* Corresponding author. Tel./fax: +86 1062923475.

E-mail addresses: greenerspan@yahoo.com.cn (N. Cao), yangmin@rcees.ac.cn (M. Yang), zhangyu@rcees.ac.cn (Y. Zhang), hujy@urban.pku.edu.cn (J. Hu), ike@see.eng.osaka-u.ac.jp (M. Ike), hirotsuji@china.meap.com (J. Hirotsuji), Matsui.Hisae@ap.MitsubishiElectric.co.jp (H. Matsui), inoue@wb.see.eng.osaka-u.ac.jp (D. Inoue), sei@see.eng.osaka-u.ac.jp (K. Sei).
} 
responses in the umu assay. The secondary effluent was also reported to induce significant reduction of hatching rates and increase of embryo lesions of exposed Japanese medaka (Oryzias latipes) embryo (Zha and Wang, 2005). One of the possible causative substance group is retinoids, which possess a chemical structure or functional properties similar to vitamin A, act as signaling molecules, and regulate many processes critical to early embryonic development (Sucov and Evans, 1995). Degitz et al. (2000) reported that $6.25 \mu \mathrm{g} / \mathrm{l}$ all trans retinoic acid could elicit higher teratological rate and mortality of exposed Xenopus laevis. Methoprene acid, a metabolic degradation product of methoprene, a pesticide, and organochlorine pesticides have been shown to bind to members of the retinoic acid receptors (RAR) (Harmon et al., 1995; Lemaire et al., 2005). Although up to now, it is not clear whether the reported increase of teratological rates of Japanese medaka embryos were related to retinoids in the secondary effluent, the above adverse ecological effects should be considered when the secondary effluent from the STPs is used as the main supplementation water source for surface water bodies.

Generally, almost all reclamation schemes have adopted some add-on technologies, among which the combination of coagulation and sand filtration (CSF) is most often introduced to the existing conventional secondary treatment, to upgrade the quality of reclaimed water. To reduce the pathogenetic risk, disinfection using chlorine is generally performed. However, the adverse effects of chlorination have caused concerns over the formation of hazardous disinfection byproducts (DBPs), and ultraviolet (UV) irradiation has been focused as a substitute for chlorination disinfection (Jolis et al., 2001). With the rapid development of membrane technologies, reclamation of municipal wastewater using ultrafiltation (UF)and reverse osmosis (RO) have become increasingly attractive (Bourgeous et al., 2001; Qin et al., 2005). UF has been known for its high efficiency in the removal of particles and some colloidal organic compounds (Bian et al., 1999; Abdessemed et al., 2000). RO is a very promising technique because it removes the majority of compounds, both organic and inorganic, with a high efficiency (Qin et al., 2005). Ozone with its strong oxidation potential is effective in disinfection, decoloration, and decomposition of organic compounds. Takanashi et al. (2002) found that ozone treatment was effective for the removal of mutagen precursors from wastewater. Petala et al. (2006) have compared the performances of different coagulants on the removal of ecotoxic and mutagenic effects from the reclaimed secondary effluent. However, systematic comparison of the existing add-on treatment technologies has not yet been carried out with respect to their respective performance in the reduction of various ecological toxicities.

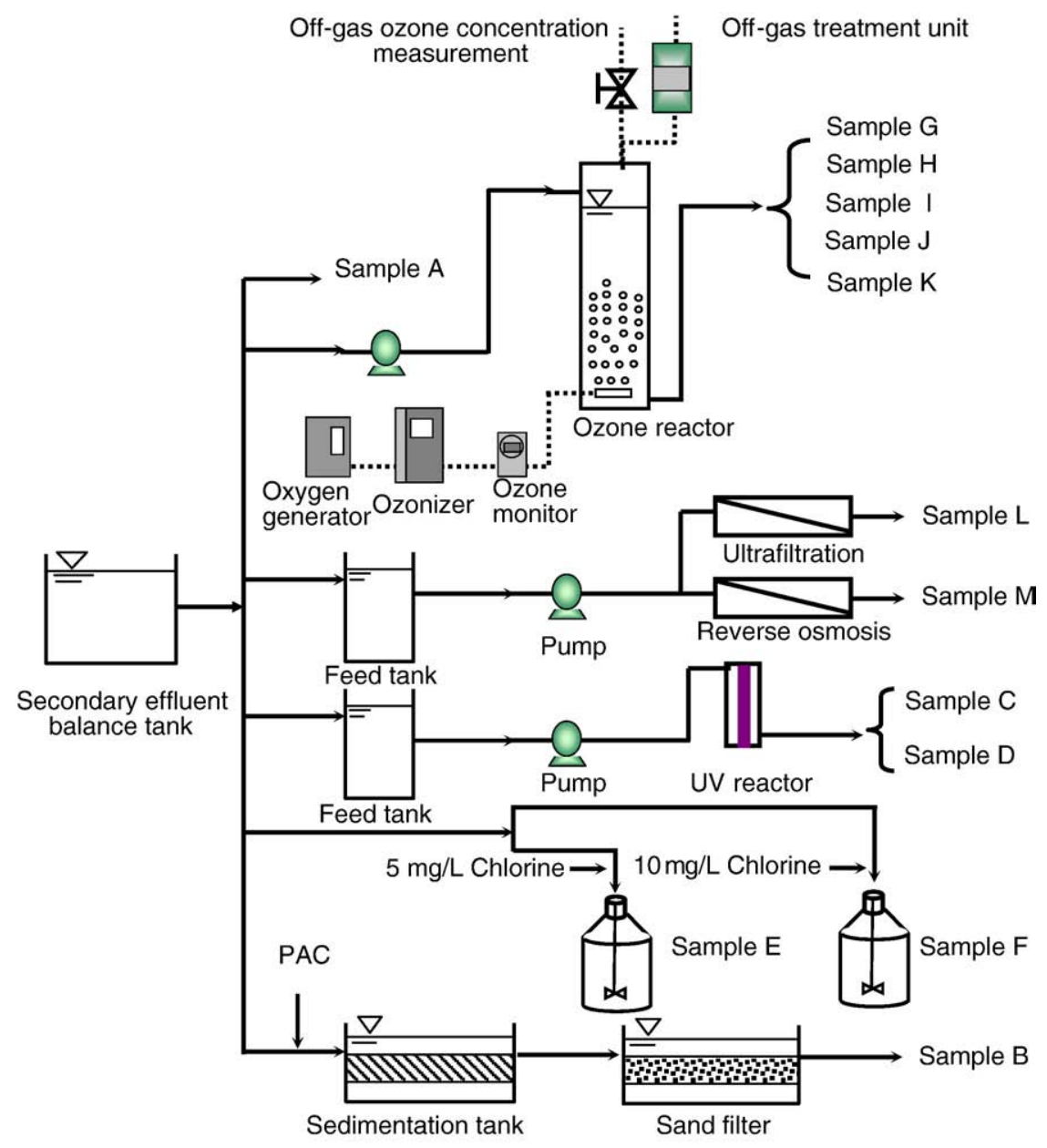

Fig. 1-Schematic diagram of reclamation treatment process and sampling. 
In this study, the acute toxicity, genotoxicity and RAR activity in the reclaimed municipal effluent were respectively evaluated using D. magna, umu test and yeast two-hybrid test, and the performance of several water treatment technologies, namely CSF, chlorination, UV, ozonation, UF and RO, was evaluated for their respective removal of the ecological toxicities from the reclaimed wastewater. The effects of treated effluents on the development of Japanese medaka embryos were also evaluated. The results of this study will be useful for the selection of suitable treatment technologies to reclaim the secondary sewage effluent for replenishment of surface water.

\section{Materials and methods}

\subsection{Water samples and chemicals}

Secondary municipal effluent was collected from an STP in Beijing, which has a treatment capacity of 1 million $\mathrm{m}^{3}$ per day with a treatment train consisting of anoxic and aerobic treatments. In this STP, $10,000 \mathrm{~m}^{3}$ per day secondary effluent was further treated with a CSF process for reuse. 100-l secondary effluent was taken from a balance tank for chlorination, UV, UF and RO treatments in laboratory and 10-1 CSF samples were taken directly from the wastewater reclamation facility (Fig. 1). Ozonation experiments were conducted using an on-site treatment system. All samples were taken on the same day, and transferred to the laboratory and kept in $4{ }^{\circ} \mathrm{C}$ for further treatments or analyses.

Analytical standards for monochloroacetic acid (MCAA), monobromoacetic acid (MBAA), dichloroacetic acid (DCAA), dibromoacetic acid (DBAA) and trichloroacetic acid (TCAA) were purchased from Acros Organics (Belgium), and chloroform, bromodichloromethane, dibromochloromethane bromoform and 1,2-dibromopropane standards were obtained from Accustandard $^{\circledR}$ Inc (USA). All of the chemical reagents used were of analytical grade if not noted specially.

\subsection{Treatment experiments}

\subsubsection{Chlorination}

A stock chlorine solution was prepared by diluting sodium hypochlorite with pure water to give a free chlorine concentration of $57 \mathrm{~g} / \mathrm{l}$. A given volume of the stock chlorine solution was added to $10 \mathrm{l}$ secondary effluent in a sealed stainless vessel under continuous mixing for $24 \mathrm{~h}$ at ambient temperature. $0.025 \mathrm{~N}$ sodium sulfite was then added to the solution to eliminate residual chlorine. Free chlorine and total chlorine were measured using "Hach Colorimeter ${ }^{\mathrm{TM}}$ II test kit for chlorine" (Hach, USA).

After Daphnia tests indicated that the acute toxicity increased following chlorination, chlorination on filtrated secondary effluent was again performed to determine the levels of DBPs formed at each chlorine dose.

\subsubsection{Ozonation}

A transparent polyvinyl chloride contact column $(\varnothing 200 \times 3 \mathrm{~m})$ with an effective volume of 78.51 was used as ozonation reactor.
An ozonizer (OS-1N, Mitsubishi Electric Co. Japan) with a rated output of $2 \mathrm{~g} / \mathrm{h}$ was used. The secondary effluent was continuously pumped into the contact column. Different ozone doses were obtained by adjusting voltage of the ozonizer. The hydraulic residence time (HRT) of the ozone treatment system was $20 \mathrm{~min}$, and samples were taken after the system was operated stably for more than $1 \mathrm{~h}$ under each condition.

Ozone concentration of feed gas was monitored using a UV ozone monitor (Hare EG-600, Ebara Jitsugyo, Japan). The residual ozone in the vent gas was adsorbed by KI adsorption, and was then determined with the sodium thiosulfate titration method together with the dissolved ozone. The ozone dose on consumption base $\left(C_{C}\right)$ was calculated by subtracting the ozone amount in the vent gas and water from that in the feed gas as Eq. (1),

$C_{C}=\frac{C_{F} \times F_{G}-Q_{O}}{F_{W}}-C_{D}$

where $C_{C}=$ ozone dose on consumption base $(\mathrm{mg} / \mathrm{l}), C_{F}=$ inlet ozone concentration $(\mathrm{mg} / \mathrm{l}), F_{\mathrm{G}}=$ flowrate of ozonized gas $(\mathrm{l} / \mathrm{min})$, $\mathrm{Q}_{\mathrm{O}}=$ residual ozone in vent gas $(\mathrm{mg} / \mathrm{min}), \mathrm{C}_{\mathrm{D}}=$ dissolved ozone concentration in water $(\mathrm{mg} / \mathrm{l})$ and $F_{\mathrm{w}}=$ flowrate of water $(1 / \mathrm{min})$. The ozone dosage mentioned in this paper stands for $C_{C}$.

\subsubsection{Membrane filtration}

The membrane filtration experiments were conducted by a flat sheet membrane apparatus (C10-T, Nitto Denko Matex, Japan) using UF membrane (50KD, Nitto Denko Matex, Japan) or RO membrane (Salt rejection 90.0\%, Nitto Denko Matex, Japan). 8 l permeate was obtained through UF and RO filtration respectively from each $20 \mathrm{l}$ secondary wastewater. The working pressure was maintained in the range of $0.3 \sim 0.5 \mathrm{MPa}$ and the flowrate was approximately $0.7 \mathrm{l} / \mathrm{min}$.

\subsubsection{UV treatment}

The secondary wastewater was pumped into a stainless steel UV column reactor with effective volume of $160 \mathrm{ml}$ and UV lamp intensity of $3.949 \mathrm{mw} / \mathrm{cm}^{2}$. Different UV irradiation doses were obtained by altering the HRT in the UV reactor (Tables 1 and 2).

\subsection{Physico-chemical analysis}

Samples were filtered through a $0.45 \mu \mathrm{m}$ membrane for analyses. The DOC was determined by Total Organic Carbon Analyzer (Phoenix, 8000, Tekmar-Dohrmann Co. USA), and UV absorbance at $254 \mathrm{~nm}$ (UV254) by UV3100 (Hitachi Ltd. Japan). $\mathrm{COD}_{\mathrm{Mn}}$ was determined according to the Standard Methods of Water and Wastewater Monitoring of China, and ammonia

\begin{tabular}{|c|c|c|c|c|c|}
\hline Sample & $\begin{array}{c}\text { Flowrate } \\
\text { l/min }\end{array}$ & $\begin{array}{l}\text { Reactor } \\
\text { volume }\end{array}$ & HRT s & $\begin{array}{c}\text { UV } \\
\text { intensity } \\
\mathrm{mw} / \mathrm{cm}^{2}\end{array}$ & $\begin{array}{c}\text { UV } \\
\text { dose }^{a} \\
\mathrm{~mJ} / \mathrm{cm}^{2}\end{array}$ \\
\hline C & 1 & $160 \mathrm{~mL}$ & 10 & 3.949 & 40 \\
\hline D & 0.4 & $160 \mathrm{~mL}$ & 24 & 3.949 & 95 \\
\hline
\end{tabular}


Table 2 - Effects of different treatments

\begin{tabular}{|c|c|c|c|c|c|c|c|c|c|}
\hline & \multirow[t]{2}{*}{ Samples } & \multicolumn{2}{|c|}{$\mathrm{COD}_{\mathrm{Mn}}$} & \multicolumn{2}{|c|}{ DOC } & \multicolumn{2}{|c|}{ UV254 } & \multicolumn{2}{|c|}{$\mathrm{NH}_{4}-\mathrm{N}$} \\
\hline & & $\mathrm{mg} / \mathrm{l}$ & $\%$ & $\mathrm{mg} / \mathrm{l}$ & $\%$ & $\mathrm{~m}^{-1}$ & $\%$ & $\mathrm{mg} / \mathrm{l}$ & $\%$ \\
\hline A & Secondary effluent & 7.0 & - & 7.9 & - & 15.2 & - & 1.9 & - \\
\hline B & CSF & a & & 6.4 & 19.0 & 13.7 & 9.9 & 1.7 & 10.5 \\
\hline $\mathrm{C}$ & UV40 $\mathrm{mJ} / \mathrm{cm}^{2}$ & a & & 7.7 & 2.0 & 13.0 & 14.0 & 1.9 & 0.0 \\
\hline $\mathrm{D}$ & UV94 mJ/cm² & a & & 7.6 & 3.0 & 12.8 & 15.4 & 1.9 & 0.0 \\
\hline $\mathrm{E}$ & Chlorination $5 \mathrm{mg} / \mathrm{l}$ & 5.8 & 17.1 & 7.6 & 3.8 & 13.3 & 12.5 & 1.9 & 0.0 \\
\hline $\mathrm{F}$ & Chlorination 10 mg/l & 5.5 & 21.7 & 7.1 & 9.3 & 11.9 & 21.8 & 1.3 & 31.6 \\
\hline G & Ozonation $2 \mathrm{mg} / \mathrm{l}$ & 5.6 & 19.5 & 6.4 & 18.2 & 11.7 & 22.9 & 1.9 & 0.0 \\
\hline $\mathrm{H}$ & Ozonation $3.8 \mathrm{mg} / \mathrm{l}$ & 5.3 & 23.7 & 6.1 & 22.7 & 10.0 & 34.3 & 1.9 & 0.0 \\
\hline I & Ozonation 8.5 mg/l & 4.9 & 29.3 & 6.0 & 23.6 & 6.0 & 60.2 & 2.1 & -10.5 \\
\hline $\mathrm{J}$ & Ozonation $11.1 \mathrm{mg} / \mathrm{l}$ & 4.8 & 31.6 & 5.7 & 27.8 & 4.7 & 68.8 & 2.3 & -21.1 \\
\hline $\mathrm{K}$ & Ozonation 15 mg/l & 4.5 & 35.2 & 5.5 & 30.6 & 4.9 & 67.5 & 2.5 & -33.7 \\
\hline $\mathrm{L}$ & UF50K & a & & 6.2 & 20.8 & 11.7 & 23.1 & 1.1 & 42.1 \\
\hline M & RO & a & & 0.9 & 88.2 & 0.2 & 99.0 & 0.1 & 94.7 \\
\hline
\end{tabular}

was determined by colorimetry using the nesslerization method.

\subsection{Chlorination DBPs analysis}

Trihalomethanes (THMs) and Haloacetic acids (HAAs) analysis were conducted using an Agilent 6890 N Gas Chromatograph (USA) equipped with an HP-5 fused silica capillary column $(0.25 \mathrm{~mm} \times 30 \mathrm{~m})$ and an electron capture detector (ECD). Four THMs, i.e., chloroform, bromodichloromethane, dibromochloromethane and bromoform were analyzed followingliquid/liquid extraction with hexane (HPLC grade, Fisher Chemicals, USA), in accordance with U.S.EPA (1990) method 551.1. Five HAAs, i.e., MCAA, MBAA, DCAA, DBAA and TCAA, were analyzed using 1,2dibromopropane as an internal standard, following liquid/liquid extraction with methyl-t-butyl-ether (MTBE, HPLC grade, Fisher Chemicals, USA) and derivatization with acidic methanol (HPLC grade, Fisher Chemicals, USA) according to U.S.EPA (2003) method 552.3.

\subsection{Concentration of wastewater samples}

Water samples before and after treatment were filtered through GF/C membrane (Whatman, UK) without $\mathrm{pH}$ adjustment, and then passed through Oasis HLB solid extraction cartridges (6 cc $500 \mathrm{mg}$, Waters, USA). The cartridges had been conditioned beforehand with $10 \mathrm{ml}$ of methanol and $10 \mathrm{ml}$ of distilled water. $2 \mathrm{l}$ of each sample was loaded to one cartridge, then dried under a nitrogen flow and eluted with $6 \mathrm{ml}$ of methanol. The eluate was dried under nitrogen flow. The dried residues were reconstituted with $200 \mu$ dimethylsulfoxide (DMSO, Ameresco, USA) and stored in the dark at $-20^{\circ} \mathrm{C}$ before used for the umu and yeast two-hybrid tests.

\section{6. umu assay}

The genotoxic effects of concentrated samples were determined with the SOS/umu bioassay (ISO 13829, 2000; Oda et al., 1985) using Salmonella typhimurium strain TA 1535/pSK1002. The test strain was provided by the Osaka Prefectural Institute of Public Health, Japan. In this strain, the multicopy plasmid
pSK 1002 bearing an umuC/lacZ gene fusion product was introduced into S. typhimurium TA1535, and the umu operon was genetically regulated by the SOS genes recA and lexA. The detailed test procedure was performed as previously described by Hu et al. (2007). In this assay, 4-nitroquinoline oxide (4-NQO) was used as positive control and DMSO as negative control.

\subsection{Yeast two-hybrid assay for RAR agonist activity}

The yeast two-hybrid assay was used to test the RAR $\alpha$ agonist activity. The ligand-binding domain of nuclear receptor of RAR $\alpha$ was cloned by RT-PCR from human mRNA. These genes were subcloned into PGBT9, so that they were in the same translational reading frame as the vector's GAL4DNA binding domain. pGBT9-NRs and pGAD424-TIF2 were integrated into Saccharomyces cerevisiae Y190, which was provided by Osaka University. The assay procedure was the same as described in a previous paper (Nishikawa et al., 1999).

\subsection{D. magna test}

D. magna bioassay was carried out using dormant eggs and the salts for preparation of standard freshwater (ISO formula) contained in the "Daphtoxkit $\mathrm{F}^{\mathrm{TM}}$ " (Microtests Inc, Belgium). Hatching of ephippia and preparation of standard freshwater were performed according to the manufacturer's instructions. The ephippia were transferred to hatching Petri dishes with $50 \mathrm{ml}$ pre-aerated standard freshwater, thereafter covered and incubated for $72 \mathrm{~h}$, at $20-22{ }^{\circ} \mathrm{C}$ under continuous illumination of $6000 \mathrm{~lx}$. Subsequently, the neonates were feed and transferred to standard freshwater with a Pasteur pipette $2 \mathrm{~h}$ before bioassays.

A dilution series of treated and untreated water samples was prepared by serial 1:1 dilution with standard freshwater. Assays were carried out in 24-well plates. Five neonates were transferred into each well, which contained $10 \mathrm{ml}$ water sample. Freshwater controls were included in every test. Tests were performed in quadruplicate. The plates were covered and incubated at $20^{\circ} \mathrm{C}$ in the dark. After $24 \mathrm{~h}$ and $48 \mathrm{~h}$ incubation, the number of dead and immobilized neonates was recorded and the percent mortality was calculated. 


\subsection{Japanese medaka (O. latipes) embryo exposure test}

Eggs were collected daily from the breeding females at less than $2 \mathrm{~h}$ after fertilization. Individual egg was carefully detached from the clusters using sucker and then inspected for fertilization using stereoscopic microscope. Eggs with the migration of oil globules to the vegetal pole were deemed to be fertilized (Kirchen and West, 1976).

Medaka embryos collected at less than $4 \mathrm{~h}$ after fertilization were exposed to the treated and untreated water samples without dilution. For each sample, 100 embryos were randomly separated into two groups with 50 embryos in each glass Petri dish $(\varnothing 15 \mathrm{~cm} \times 2 \mathrm{~cm})$ containing $100 \mathrm{ml}$ water sample, and then incubated at $25{ }^{\circ} \mathrm{C}$ under a $16: 8 \mathrm{~h}$ light:dark photoperiod. The water samples were renewed every single day until all the able embryos hatched. Larvae were fed with newly hatched brine shrimp once a day. The embryos and larvae were examined daily for mortality under a stereoscopic microscope, and the dead embryos were discarded. Embryos cultured in tap water dechlorinated with granular activated carbon were used as control.

\section{Results and discussion}

\subsection{Water quality}

Water quality parameters before and after treatments are presented in Table 2. It is clear that RO filtration could significantly improve water quality with $88.2 \%$ of DOC, $94.7 \%$ of ammonia and $99 \%$ of UV254 removals from the secondary effluent. The DOC and UV254 removals of ozonation at a dose of $2 \mathrm{mg} / \mathrm{l}(18.2 \%$ and $22.9 \%)$ were equivalent to those of UF treatment (20.8\% and 23.1\%). The increase of ozone dose from $2 \mathrm{mg} / \mathrm{l}$ to $8.5 \mathrm{mg} / \mathrm{l}$ led to the increase of UV254 removal to $60.2 \%$. The DOC removal, however, was not improved so markedly. The CSF treatment could remove $19.0 \%$ of DOC and $9.9 \%$ of UV254. UV irradiation and chlorination were not so effective for DOC removal (<10\%), but could remove a little UV254 (from $14.0 \%$ to $21.8 \%$ according to doses). Chlorination at a chlorine dose of $10 \mathrm{mg} / \mathrm{l}$ led to a removal of ammonia of $31.6 \%$, which should be caused by break point reaction.

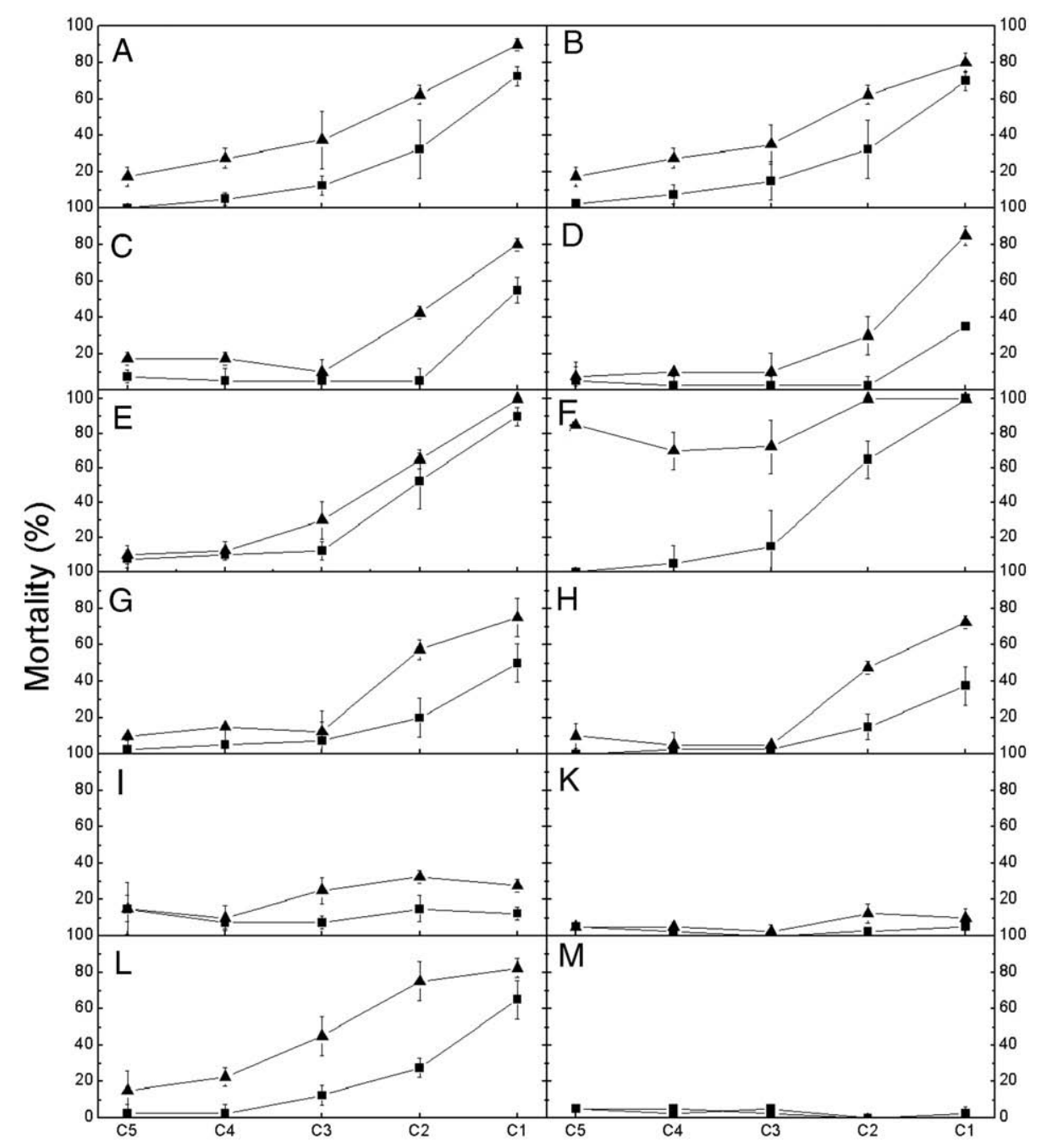

Fig. 2-Dose-mortality curves of D. magana neonates exposed to different treated effluents for $24 \mathrm{~h} \mathrm{a}$ and $48 \mathrm{~h} \Delta . \mathrm{C} 1, \mathrm{C} 2, \mathrm{C} 3, \mathrm{C4}$, and C5 represent $100 \%, 50 \%, 25 \%, 12.5 \%$, and $6.25 \%$ of the effluents diluted with standard freshwater. The data are percent mortalities corrected for the natural mortality; values are the means \pm SE of 3 independent experiments, each with four replicates. 


\subsection{Acute invertebrate toxicity}

Fig. 2A shows that there exists a clear dose-response effect between the fraction of the secondary effluent and the mortality of neonates, and that the mortality of neonates expose to the secondary effluent without dilution for $24 \mathrm{~h}$ and $48 \mathrm{~h}$ was $72.5 \%$ and $90.0 \%$, respectively, indicating the high acute invertebrate toxicity of the secondary effluent to neonates. Ozonation was effective for the reduction of acute toxicity from the secondary effluent. The 48-h neonate mortality was almost completely removed for the samples diluted by 4 times at an ozone dose of $4 \mathrm{mg} / \mathrm{l}$ (Fig. 2H). The dose-response effect between the fraction of the secondary effluent and the mortality of neonates almost disappeared at an ozone dose of $8 \mathrm{mg} / \mathrm{l}$ (Fig. 2I), and ozone dose of $15 \mathrm{mg} / \mathrm{l}$ (Fig. 2K) reduced the mortality nearly to blank level, suggesting that such an ozone dose might be sufficient for the complete removal of the acute toxicity from the secondary effluent.

It is clear that RO treatment was very effective for the removal of acute toxicity from the secondary effluent (Fig. 2M). UV treatment resulted in a minor decrease of 24-h mortality while little effect was observed on 48-h mortality, which was in accordance with the effect of ozonation at an ozone dose of $2 \mathrm{mg} / \mathrm{l}$ (Fig. 2C, D and G). It is possible that the UV254 removal by UV irradiation might be related with the reduction of acute toxicity. On the other hand, the mortality of neonates was not perceptibly improved by the treatments of CSF and UF although these two treatments could also remove DOC and UV254 to some extent. It is possible that the removed compounds in these two processes might be different from those in UV and ozone processes.

It is of concern that the mortality of neonates exposed to the chlorinated secondary effluent increased in spite of the moderate removal of UV254. The 24 -h and 48 -h mortalities of the secondary effluent increased from the approximately $80 \%$ and $90 \%$ to $90 \%$ and $100 \%$ after chlorination at a $5 \mathrm{mg} / \mathrm{l}$ chlorine dose. Chlorination at $10 \mathrm{mg} / \mathrm{l}$ led to a mortality of $100 \%$ for both the $24-\mathrm{h}$ and 48 -h cultivation. It should be noted that the 48-h mortality of neonates in system $\mathrm{F}$ was as high as $70 \%$ even when the chlorinated water was diluted by 4 times. Since dechlorination was performed after the chlorination treatment, the acute toxicity should not be originated from the residual chlorine or chloramines. It is possible that the

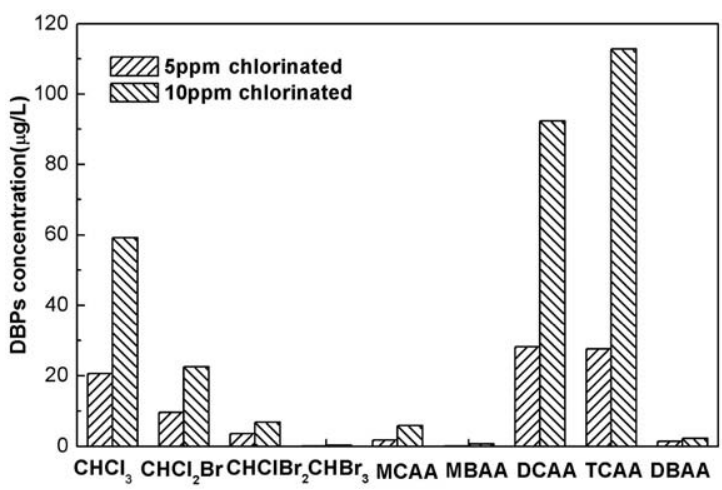

Fig. 3-THMs and HAAs measured in the chlorinated secondary effluent.

\begin{tabular}{|c|c|c|c|}
\hline $\begin{array}{l}\text { Potential } \\
\text { chlorination DBPs }\end{array}$ & test & $\begin{array}{l}\text { Value } \\
(\mathrm{mg} / \mathrm{l})\end{array}$ & Reference \\
\hline Trichloromethane & 48 h-LC50 & 229.21 & Genoni, 1997 \\
\hline Trichloromethane & $24 \mathrm{~h}-\mathrm{LC} 50$ & 64.23 & $\begin{array}{l}\text { Guilhermino } \\
\text { et al., } 2000\end{array}$ \\
\hline Trichloromethane & 24 h-EC50 & 573.014 & $\begin{array}{l}\text { Guilhermino } \\
\text { et al., } 2000\end{array}$ \\
\hline 1,2-Dichloropropane & 48 h-LC50 & 49.659 & Genoni, 1997 \\
\hline 1,2-Dichlorobenzene & 48 h-LC50 & 3.528 & Genoni, 1997 \\
\hline 2,4,5-Trichlorophenol & 48 h-LC50 & 1.801 & Genoni, 1997 \\
\hline Chloroacetate & 48 h-LC50 & 76.998 & Genoni, 1997 \\
\hline 1,2,3-Trichloropropane & 48 h-LC50 & 35.366 & Genoni, 1997 \\
\hline Formaldehyde & 48 h-EC50 & 29 & $\begin{array}{l}\text { Janssen and } \\
\text { Persoone, } 1993\end{array}$ \\
\hline Formaldehyde & $24 \mathrm{~h}-\mathrm{EC} 50$ & 57 & $\begin{array}{l}\text { Janssen and } \\
\text { Persoone, } 1993\end{array}$ \\
\hline
\end{tabular}

increased acute toxicity was originated from the formation of some chlorination by-products. So, the DBP (4 THMs and 5 HAAs) formation abilities of the secondary effluent were evaluated, and the results are shown in Fig. 3. $\mathrm{CHCl}_{3}, \mathrm{DCAA}$ and TCAA were found to be the major ones among the 9 DBPs, and their concentrations increased markedly when the chlorine dose was increased from $5 \mathrm{mg} / \mathrm{l}$ to $10 \mathrm{mg} / \mathrm{l}$. However, as shown in Table 3, the LC50 values of the conventional DBPs for D. magna are in $\mathrm{mg} / \mathrm{l}$ levels, which are approximately 2 or 3 orders higher than the concentrations in the chlorinated samples. So, these conventional DBPs might not be the main cause for the increase of acute toxicity after chlorination. The secondary effluent is a very complex matrix, and its chlorinated DBPs have not yet been well understood. The formation of some unknown DBPs and the interactive effects among different DBPs might be responsible for the increased toxicities.

\subsection{Genotoxicity}

Genotoxicity of the secondary effluent before and after treatments was evaluated using $S$. typhimurium strain TA $1535 \mathrm{r} / \mathrm{pSK} 1002$ without addition of metabolic activation system S9 mix, and is presented in Fig. 4. The genotoxic response induced by the secondary effluent was approximately 6 times

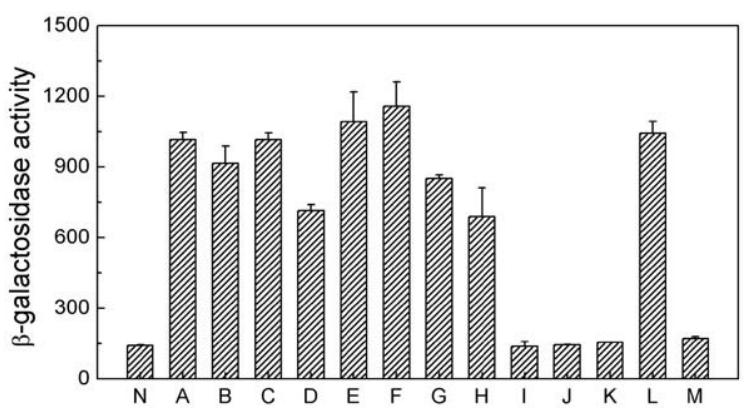

Fig. 4-Induced genotoxic activity of different treated effluents. $\mathrm{N}$ means the negative control; the values are the means $\pm \mathrm{SE}$ of 3 experiments. 


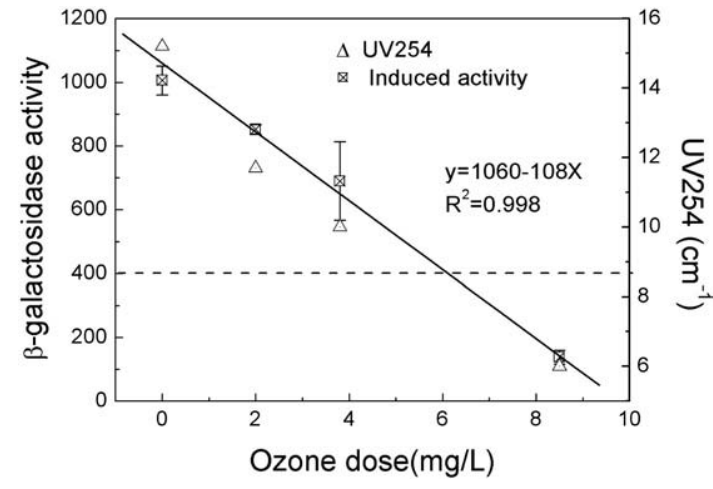

Fig. 5-Induced mutagenic activity and UV 254 under different ozone dose. Dash line means the positive value of the umu test.

higher than that of the negative control, indicating that the secondary effluent had a relatively high genotoxicity. It is clear that ozonation and RO were the only two methods that are effective for the reduction of genotoxicity from the secondary effluent. Ozonation at an ozone dose of $8.5 \mathrm{mg} / \mathrm{l}$ and the RO treatment could almost reduce the genotoxic activity to the negative control level. The evolution of genotoxic activity is plotted against ozone dose together with UV254 (Fig. 5). It is clear that the induced activity was linearly reduced together with UV254 with the increase of ozone dose. According to this plot, it is speculated that an ozone dose of $5.9 \mathrm{mg} / \mathrm{l}$ could reduce the genotoxic potential from positive to negative. The above results suggested that the genotoxicity in the secondary effluent might be related with presence of some unsaturated compounds.

On the other hand, the CSF, UF with 50000D and UV irradiation at $40 \mathrm{mj} / \mathrm{cm}^{2}$ did not perceptibly change the genotoxic potential of the secondary effluent; while UV irradiation at $95 \mathrm{mj} / \mathrm{cm}^{2}$ could remove $29.6 \%$ genotoxic potential from the secondary effluent (Fig. 4). UV irradiation might have broken some unsaturated structures of organic compounds which possessed genotoxicity. Although chlorination led to the decrease of UV254, the genotoxic potential increased by $8.7 \%$ for $5 \mathrm{mg} / \mathrm{l}$ chlorine dose and $15.2 \%$ for $10 \mathrm{mg} / \mathrm{l}$ chlorine dose, respectively. The existence of ammonia in the

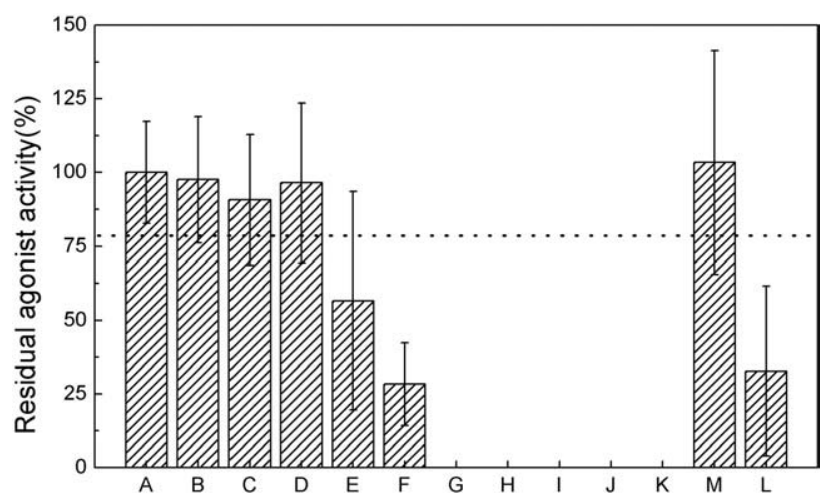

Fig. 6-RAR agonist activity removal by different technologies. The values are the means \pm SE of 3 experiments. secondary effluent caused the formation of chloramines during chlorination, which may produce DBPs with toxicities far more potent than those currently regulated (Plewa et al., 2004; Choi and Valentine, 2002; Richardson et al., 2007). Further works are necessary to elucidate the reason for the increase of genetic toxicity.

\subsection{RAR $\alpha$ agonist activity}

The RAR $\alpha$ activities of the secondary effluent as well as treated effluents were determined. The secondary effluent showed weak agonist activity, and the all trans retinoic acid equivalent was $13.4 \pm 2.7 \mathrm{ng} / \mathrm{l}$. Degitz et al. (2000) reported that $6.25 \mu \mathrm{g} / \mathrm{l}$ all trans retinoic acid could elicit higher teratological rates and mortality of exposed X. laevis. However, research regarding the agonist activities in the secondary effluent has been very limited. Fig. 6 shows the RAR $\alpha$ agonist activity removal performance of different reclamation technologies. UV, CSF and UF could not remarkably remove the RAR $\alpha$ activity, while chlorination treatment could remove the activity to some extent. Ozonation was very effective to reduce the RAR $\alpha$ agonist activity, and the activity was almost completely removed even at an ozone dose of $2 \mathrm{mg} / \mathrm{l}$.

\subsection{Effects on Japanese medaka embryos development}

As shown in Fig. 7, the 4-day mortality in the secondary effluent was $22 \%$, which was effectively promoted through RO treatment to a level equivalent to that of control. The 4-day mortality remained almost unchanged for CSF, UV and UF treatments. Again, the 4-day mortality increased to $32 \%$ for chlorination at $10 \mathrm{mg} / \mathrm{l}$. Surprisingly, ozonation remarkably increased the mortality: the mortality was $32 \%$ for ozonation at $2 \mathrm{mg} / \mathrm{l}$, which increased to $52 \%$ at $4 \mathrm{mg} / \mathrm{l}$. But further increase of ozone dose did not lead to the increase of mortality.

Abnormalities of embryos were observed from the fourth day (Fig. 7). The lesions would, to some extent, affect the hatching success of embryos and the growth and survival of the larvae (Kjørsvik et al., 1990). Absolute majority of embryos were normal in the controls and RO effluent (Fig. 8a), in which

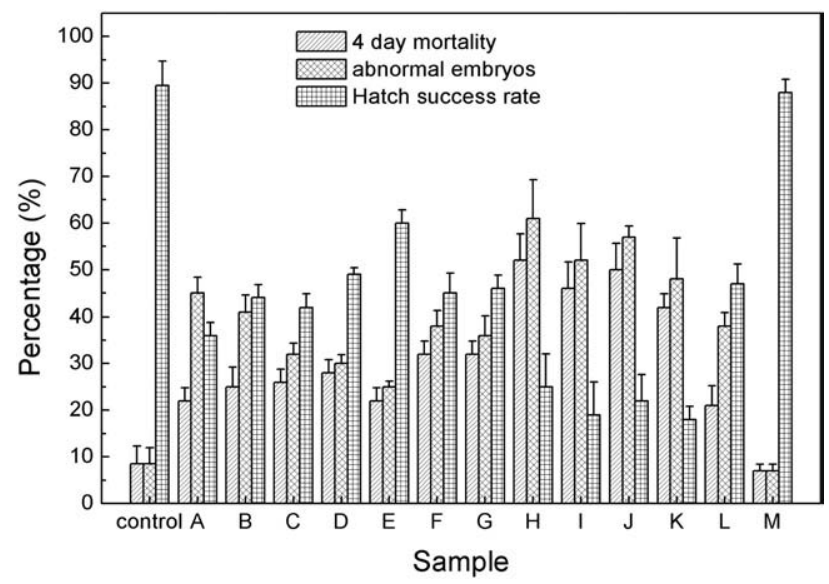

Fig. 7-The effects of different treatments on Medaka embryos development. Values are the means \pm SE of 2 independent experiments, each with 50 embryos. 

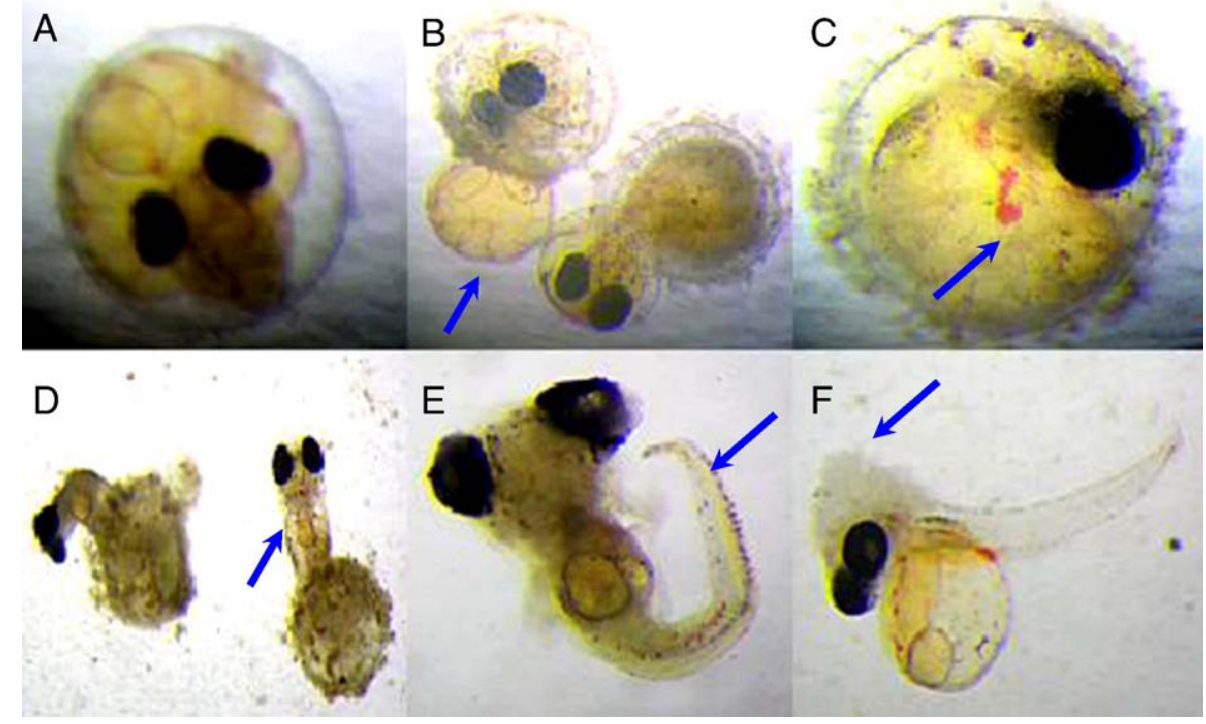

Fig. 8-Teratological development forms of embryos: (A) normal embryos; (B) lesion embryos with extruded vesicle; (C) lesion embryos with hemorrhage; (D) head-first hatch out pattern; (E) deformed larvae with impaired spine; (F) deformed larvae with cranial herniation.

all abnormal eggs died before the fourth day and no more was observed later. The secondary effluent elicited several morphologic effects on embryos as well as the effluents of other treatment technologies as shown in Fig. 8. Most abnormal embryos emerging as a vesicle extruding outside of yolk sphere wall (Fig. 8b) ended up with death. Internal hemorrhage (Fig. 8c), which was the rare case and mainly occurred in the secondary effluent and chlorinated samples, did not statistically interfere with hatching success (Table 4). In Fig. 8d cases, the embryos did not hatch out in the normal tail-first pattern, but instead hatched out in an abnormal head-first pattern. These embryos showed progressing embryonic development but most failed to hatch. Although some embryos survived the hatching process, they were

Table 4-Statistics of abnormal embryos observed in different treated effluents

Sample Teratological development form of the embryos Hemorrhage Extruding Head-first Cranial

\begin{tabular}{lllll}
\hline $\mathrm{A}$ & + & ++ & + & - \\
$\mathrm{B}$ & + & ++ & + & - \\
$\mathrm{C}$ & - & + & + & - \\
$\mathrm{D}$ & - & + & + & - \\
$\mathrm{E}$ & - & + & + & - \\
$\mathrm{F}$ & + & ++ & + & - \\
$\mathrm{G}$ & - & + & + & - \\
$\mathrm{H}$ & - & + & + & - \\
$\mathrm{I}$ & - & + & + & - \\
$\mathrm{J}$ & - & + & ++ & + \\
$\mathrm{K}$ & - & + & ++ & + \\
$\mathrm{L}$ & - & + & - & - \\
$\mathrm{M}$ & - & - & - & -
\end{tabular}

"-"means absence of case; "+"means cases between 1 and 5; "++" means cases between 6 and 10 . unable to survive for more than 2 days due to their greatly impaired swimming ability (Fig. 8e). The case of Fig. 8d was frequently observed in ozone treated effluents, which consequently leaded to the decrease of hatching success rate. A more severe developmental effect on embryos showing cranial herniation (Fig. 8f) was observed in high dose ozone treated water. It is not clear whether the cranial herniation resulted from skull development defects or impairment during the abnormal head-first hatching process.

The hatching rate, which is an important parameter for indicating the quality of larvae and the survival of the target species, is sensitive to changes of the environment (Detlaf et al., 1993). The hatching success rate of embryos exposed to the secondary effluent was $36 \%$, which was significantly lower than that of the controls (89.5\%). Comparing with the secondary effluent, CSF, UV, chlorination, UF and ozonation at $2 \mathrm{mg} / \mathrm{l}$ could elevate the hatching success rate by $10 \%$ or so. However, the increase of ozone dose led to the decrease of the hatching rate significantly. Among all of the treatment technologies, only RO could elevate the hatching success rate of embryos nearly to the level of the controls. Grotmol and Totland (2000) found that the survival rate of Hippoglossus hippoglossus embryos increased after treated with $4 \mathrm{mg} / \mathrm{l}$ ozone for $0.5 \mathrm{~min}$ for disinfection, but decreased under higher ozone doses. In this work, residual ozone was erased before exposing the eggs. Thus, it is speculated that some byproducts formed during ozonation caused the decrease of hatching success rate. Organic ozonation byproducts reported include aldehydes, ketones, ketoaldehydes, carboxylic acids, aldo acids, keto acids, hydroxy acids, alcohols, esters, and alkanes (Coleman et al., 1992; Killops, 1986). It is speculated that these ozonation byproducts with high polar and small molecular weight might have easier access into the embryos, disturbing the normal development of embryos. Further studies are required to clarify the ozonation byproducts responsible for the teratogenic development of embryos, and to find an effective 
abatement method for the removal of the possible byproducts. As small molecular ozonation byproducts are usually biodegradable, it is possible that a subsequent biofilter might be able to remove these compounds.

\section{Conclusion}

Two in vitro assay and two in vivo assay showed that the secondary effluent have genotoxicity, weak RAR $\alpha$ activity, acute invertebrate toxicity as well as remarkably adverse effect on medaka embryos development. RO is the most effective technologies to remove most toxicants from the secondary effluent. CFS and UF showed little effect on the genotoxicity, RAR $\alpha$ activity and acute invertebrate toxicity, while UV elicited abatement of genotoxicity only at a high dose. Ozonation was found to be effective to remove the genotoxicity, RAR $\alpha$ agonist activity and acute invertebrate toxicity, but the ozonated effluent at higher than $4 \mathrm{mg} / \mathrm{l}$ would elicit the significant decrease of hatching success of medaka embryos, which requires a subsequent treatment to remove the bio-available byproducts. Increase of genotoxicity and acute invertebrate toxicity were observed in chlorinated effluents, which might be caused by the production of some chlorinated byproducts.

\section{Acknowledgments}

This study was financially supported by the National Natural Science Foundation of China (No. 50525824 and 20777002), the Tianjin Special Innovation Fund (No.06FZZDSH00900) and the New Energy and Industrial Technology Development Organization of Japan (NEDO). The authors thank Dr. Jun-ichi Nishikawa, Osaka University, for his kindly provision and instruction of the yeast two-hybrid assay.

\section{R E F E R E N C E S}

Abdessemed D, Nezzal G, Aim RB. Coagulation-adsorption-ultrafiltration for wastewater treatment and reuse. Desalination 2000;131:307-14.

Aguayo S, Munoz MJ, de la Torre A, Roset J, de la Pena E, Carballo M. Identification of organic compounds and ecotoxicological assessment of sewage treatment plants (STP) effluents. Sci Total Environ 2004;328:69-81.

Bian R, Watanabe Y, Tambo N, Ozawa G. Removal of humic substances by UF and NF membrane systems. Water Sci Technol 1999;40:121-9.

Bourgeous KN, Darby JL, Tchobanoglous G. Ultrafiltration of wastewater: effects of particles, mode of operation, and backwash effectiveness. Water Res 2001;35:77-90.

Choi J, Valentine RL. Formation of $\mathrm{N}$-nitrosodimethylamine (NDMA) from reaction of monochloramine: a new disinfection by-product. Water Res 2002;36:817-24.

Coleman WE, Munch JW, Ringhand HP, Kaylor WH, Mitchell DE. Ozonation/post-chlorination of humic acid: a model for predicting drinking water disinfection by-products. Ozone Sci Eng 1992;14:51-69.

Degitz SJ, Kosian PA, Makynen EA, Jensen KM, Ankley GT. Stage- and species-specific developmental toxicity of all-trans retinoic acid in four native North American ranids and Xenopus laevis. Toxicol Sci 2000;57:264-74.

Detlaf TA, Ginzburg AS, Shmalgauzen OI. Sturgeon fishes: developmental biology and aquaculture. Berlin: Springer-verlag; 1993. $300 \mathrm{pp}$.

Dizer H, Wittekindt E, Fischer B, Hansen PD. The cytotoxic and genotoxic potential of surface water and wastewater effluents as determined by bioluminescence, umu-assays and selected biomarkers. Chemosphere 2002;46:225-33.

Genoni GP. Influence of the energy relationships of organic compounds on toxicity to the Cladoceran Daphnia magna and the fish Pimephales promelas. Ecotoxicol Environ Saf 1997;36:27-37.

Grotmol S, Totland GK. Surface disinfection of Atlantic halibut Hippoglossus hippoglossus eggs with ozonated sea-water inactivates nodavirus and increases survival of the larvae. Dis Aquat Org 2000;39:89-96.

Guilhermino L, Diamantino T, Silva MC, Soares AMCM. Acute toxicity test with Daphnia magna: an alternative to mammals in the prescreening of chemical toxicity? Ecotoxicol Environ Saf 2000;46:357-62.

Harmon MA, Boehm MF, Heyman RA, Mangelsdorf DJ. Activation of mammalian retonid $\times$ receptors by the insect growth regulator methoprene. P Natl Acad Sci USA 1995;92:6157-60.

Hu J, Wang W, Zhu Z, Chang H, Pan F, Lin B. Quantitative structure-activity relationship model for prediction of genotoxic potential for quinolone antibacterials. Environ Sci Technol 2007;41:4806-12.

ISO 13829-2000. International standard: water quality-determination of genotoxicity of water and waste water using the umu-test; 2000.

Janssen CR, Persoone G. Rapid toxicity screening tests for aquatic biota. 1.Methodology and experiments with D. magna. Environ Toxicol Chem 1993;12:711-7.

Jolis D, Lam C, Pitt P. Particle effects on ultraviolet disinfection of coliform bacteria in recycled water. Water Environ Res 2001;73:233-6.

Killops SD. Volatile ozonization products of aqueous humic material. Water Res 1986;20:153-65.

Kirchen RV, West WR. The Japanese medaka: its care and development. Carolina Biological Supply Company, Burlington NC; 1976. p. 1-58.

Kjørsvik E, Mangor-Jensen A, Holmefjord I. Egg quality in fishes. Adv Mar Biol 1990;26:71-113.

Lemaire G, Balaguer P, Michel S, Rahmani R. Activation of retinoic acid receptor-dependent transcription by organochlorine pesticides. Toxicol Appl Pharmacol 2005;202:38-49.

Nishikawa J, Saito K, Goto J, Dakeyama F, Matsuo M, Nishihara T. New screening methods for chemicals with hormonal activities using interaction of nuclear hormone receptor with coactivator. Toxicol Appl Pharmacol 1999;154:76-83.

Oda Y, Nakamura S, Oki I, Kato T, Shinagawa H. Evaluation of the new system (umu-test) for the detection of environmental mutagens and carcinogens. Mutat Res 1985;147:219-29.

Petala M, Samaras P, Kungolos A, Zouboulis A, Papadopoulos A, Sakellaropoulos GP. The effect of coagulation on the toxicity and genotoxicity of reclaimed municipal effluents. Chemosphere 2006;65:1007-18.

Plewa MJ, Wagner ED, Richardson SD, Thruston Jr AD, Woo YT, McKague AB. Chemical and biological characterization of newly discovered iodoacid drinking water disinfection byproducts. Environ Sci Technol 2004;38:4713-22.

Qin JJ, Oo MH, Wai MN, Kekre KA. TOC removal in reclamation of municipal wastewater by RO. Sep Purif Technol 2005;46:125-8.

Richardson SD, Plewa MJ, Wagner ED, Schoeny R, DeMarini DM. Occurrence, genotoxicity, and carcinogenicity of regulated and emerging disinfection by-products in drinking water: a review and roadmap for research. Mutat Res 2007;636:178-242. 
Sucov HM, Evans RM. Retinoic acid and retinoic acid receptors in development. Mol Neurobiol 1995;10:169-84.

Takanashi H, Mayumi M, Kato M, Hirata M, Hano T. Removal of mutagen precursor from wastewater by activated sludge and oxidation treatment. Water Sci Technol 2002;46:389-94.

U.S.EPA. Determination of chlorination disinfection byproducts and chlorinated solvents in drinking water by liquid-liquid extraction and gas chromatography with electron-capture detection. Environmental Monitoring Systems Laboratory Office of Research and Development, Method 551.1.; 1990.
U.S.EPA. Determination of haloacetic acids and dalapon in drinking water by liquid-liquid microextraction derivatization, and gas chromatography with electron capture detection. Technical Support Center Office of Ground Water and Drinking water, Method 552.3; 2003.

Zha J, Wang Z. Assessing technological feasibility for wastewater reclamation based on early life stage toxicity of Japanese medaka (Oryzias latipes). Agric Ecosyst Environ 2005;107:187-98. 